\title{
Penerapan Model Vorteks Gelas Termodifikasi pada Kristal Tunggal Superkonduktor $\mathrm{Bi}_{2} \mathrm{Sr}_{2} \mathrm{CaCu}_{2} \mathbf{O}_{8+\delta}$
}

\author{
Suryo E. Cahyoingrat dan Darminto* \\ Jurusan Fisika, Fakultas Matematika dan ilmu Pengetahuan Alam \\ Institut Teknologi Sepuluh Nopember, Kampus ITS Sukolilo, Surabaya 60111
}

Intisari

\begin{abstract}
Analisis sistematis telah dilakukan pada data resisitivitas dari dua sampel kristal tunggal $\mathrm{Bi}_{2} \mathrm{Sr}_{2} \mathrm{CaCu}_{2} \mathrm{O}_{8+\delta}$ (Bi-2212) dengan kandungan oksigen berbeda yang mempunyai $\mathrm{T}_{c}=93 \mathrm{~K}$ dan $70 \mathrm{~K}$ dalam pengaruh medan magnetik antara $0 \leq \mathrm{H} \leq 40$ kOe yang berarah sejajar sumbu-c kristal. Model dengan rumusan panjang koherensi termodifikasi yang diperkenalkan oleh Rydh, dkk. telah memberikan penjelasan yang konsisten perilaku vorteks gelas dengan memberikan nilai eksponen kritis (s) yakni 4,7 dan 2,0 berturut-turut untuk sampel yang bersesuaian. Selain itu penskalaan kurva pada model ini memberikan nilai parameter pining $(\beta)$ berturut-turut 0,45 dan 0,54 untuk kedua kristal.
\end{abstract}

KATA KUNCI: Bi-2212, voteks gelas, doping oksigen, anisotropi, disorder

\section{PENDAHULUAN}

Salah satu topik kajian pada bahan superkonduktor suhu kritis ringgi (SKST) yang banyak dilakukan dalam satu dekade terakhir ini adalah karakteristik resistivitas dalam medan magnet (magneto-resistivity) pada fase vorteks gelas [1]. Bahan yang terutama digunakan sebagai model sistem SKST adalah kristal $\mathrm{YBa}_{2} \mathrm{Cu}_{3} \mathrm{O}_{7-\delta}(\mathrm{Y}-123)$ yang anisotropinya lebih rendah serta $\mathrm{Bi}_{2} \mathrm{Sr}_{2} \mathrm{CaCu}_{2} \mathrm{O}_{8+\delta}(\mathrm{Bi}-2212)$ dengan anisotropi yang lebih tinggi. Sejumlah karakteristik superkonduktivitas yang telah ditunjukkan oleh Y-123 ternyata sangat berbeda jika diterapkan pada $\mathrm{Bi}-2212$, terlebih dengan adanya penambahan doping oksigen di dalamnya [2].

Dalam fase vorteks gelas, anggapan mendasar fase gelas yang diperkenalkan oleh Fisher, dkk. [3] adalah panjang koherensi vorteks gelas $\xi_{g}(\mathrm{~T})$ pada suhu transisi gelas $\mathrm{T}_{g}(\mathrm{H})$ yang dinyatakan oleh :

$$
\xi_{g}(T) \propto\left|T-T_{g}\right|^{-\nu}
$$

dengan $\nu$ adalah eksponen kritis statis dan $\mathrm{T}_{g}$ adalah suhu transisi gelas [3]. Pada fase vorteks cair rapat arus yang rendah memberikan resistivitas fase gelas yang linier seperti dinyatakan oleh persamaan :

$$
\rho_{g}(T) \propto\left|T-T_{g}\right|^{\nu(z+2-d)}
$$

dengan $\mathrm{z}$ adalah eksponen kritis dinamis dan d merupakan dimensionalitas.

\footnotetext{
*E-MAIL: darminto33@yahoo.com
}

Rydh, dkk.[3] telah menunjukkan bahwa penjelasan yang konsisten dan lebih lengkap dari resistivitas fase gelas dapat diperoleh dengan memperkenalkan persamaan $\xi_{g}$ yang termodifikasi. Hal ini mengacu bahwa vorteks gelas sebagai daerah yang terpisah dari vorteks cair melalui transisi fase orde kedua yang memperlihatkan penskalaan gelas (glass-scaling). Seperti yang telah diajukan oleh Rydh, dkk.[3] bahwa energi penggerak transisi gelas timbul dari perbedaan energi $\left(\mathrm{k}_{B} \mathrm{~T}\right.$ $\mathrm{U}_{\circ}$ ), dan $\mathrm{U}_{\circ}$ menyatakan energi pining (pinning energy) yang tak bergantung pada besarnya arus listrik, sebagai pengganti perbedaan suhu (T - $\mathrm{T}_{g}$ ) dalam model Fisher, dkk. [4-6].

Dengan asumsi bahwa pining antara lain dapat disebabkan oleh ketakteraturan yang random (quenched disorder), $\mathrm{U}_{o}$ merupakan energi sistem vorteks yang mempunyai sifat antara elastis dan plastis atau keduanya. Pengaruh suhu akan mengurangi efek pining yang membuat sistem vorteks menjadi tidak stabil untuk melawan efek fluktuasi termal ketika energi termal $\mathrm{k}_{B} \mathrm{~T}$ menjadi lebih besar dari daripada $\mathrm{U}_{o}(\mathrm{~T})$. Transisi vorteks dari fase padat ke fase cair terjadi ketika dua nilai energi ini sama besar, $\mathrm{U}_{o}\left(\mathrm{H}, \mathrm{T}_{g}\right)=\mathrm{k}_{B} \mathrm{~T}_{g}$. Ini merupakan analogi dari kasus pelelehan vorteks (vortex melting) di mana pining demikian tereduksi dan dapat diabaikan, serta suhu pelelehan $\left(\mathrm{T}_{m}\right)$ dapat ditentukan dengan membandingkan energi termal dan energi elastis.

Selanjutnya, titik awal dari modifikasi model Fisher, dkk. adalah asumsi bahwa secara praktis Persamaan (1) dapat dimodifikasi sebagai berikut:

$$
\xi_{g}=\xi_{g}(0)\left|\frac{k_{B} T}{U_{\circ}}-1\right|^{-\nu}
$$

Dalam persamaan ini telah dipertimbangkan perbedaan energi yang lebih tepat pada masing-masing suhu dan oleh karena dapat berlaku pada rentang suhu yang lebih besar hingga menjangkau sekitar $\mathrm{T}_{g}$. Persamaan (3) dapat dikembalikan ke 
dalam Persamaan (1) jika $\mathrm{U}_{o}=\mathrm{U}_{o}(\mathrm{H}, \mathrm{T})$ didekati dengan nilai $\mathrm{k}_{B} \mathrm{~T}_{g}(\mathrm{H})$ pada garis transisi gelas.

Seperti halnya dalam Persamaan (2), dalam model Rydh, dkk.[3] diperoleh persamaan resistivitas sebagai berikut :

$$
\rho_{g}=\rho_{o}\left|\frac{1}{x}-1\right|^{\nu(z+2-d)}
$$

dengan $\mathrm{x}$ merupakan merupakan fungsi dari perbandingan energi berikut :

$$
x=\frac{U_{\circ}(H, T)}{k_{B} T}
$$

Kebergantungan $\mathrm{U}_{o}$ pada suhu dan medan dapat diperkirakan pada tingkat-tingkat resistivitas yang tertentu di dalam daerah fase gelas, di mana pada daerah tersebut

$$
x(\rho)=\text { konstan }=\frac{U_{\circ}(H, T)}{k_{B} T}
$$

dengan nilai $\mathrm{x}=1$, dan untuk $\mathrm{x}>1$ vorteks berada pada daerah cair. Untuk mendapatkan kebergantungan pada medan dan suhu, Rydh, dkk.[3] membuat persamaan umum yang dinyatakan dengan :

$$
U_{\circ}(H, T)=k_{B} T_{c} \frac{f(t)}{\left(H / H_{\circ}\right)^{\beta}}
$$

dengan $\mathrm{f}(\mathrm{t})$ adalah fungsi dari $\frac{T}{T_{c}}$ dan $\mathrm{H}_{\circ}$ serta $\beta$ merupakan konstanta yang tidak bergantung pada medan dan suhu. Pada nilai $\mathrm{x}=1$ (daerah gelas), Persamaan (6) memberikan persamaan garis medan transisi gelas $\mathrm{H}_{g}(\mathrm{~T})$ :

$$
H_{g}(T)=H_{\circ}\left[\frac{f(t)}{t}\right]^{1 / \beta}
$$

berdasarkan rumusan empirik pada garis gelas diperoleh bentuk :

$$
H_{g}(T)=H_{\circ}\left[\frac{1-t}{t}\right]^{\alpha}
$$

Dengan demikian, dari Persamaan (7) dan (8) diperoleh hubungan $\beta=1 / \alpha$ dan $\mathrm{f}(\mathrm{t})=1-\mathrm{t}$. Untuk sembarang tingkat resistivitas $\mathrm{x}$, hubungan antara $\mathrm{H}$ dan $\mathrm{t}$ menjadi :

$$
H=H_{\circ} x^{-1 / \beta}\left[\frac{f(t)}{t}\right]^{1 / \beta}
$$

dengan prefaktor yang dinyatakan oleh :

$$
H_{\rho}(x)=H_{\circ} x^{-1 / \beta}
$$

Selanjutnya, jika persamaan ini dikembalikan ke Persamaan (9) akan diperoleh :

$$
H_{\rho}=H\left[\frac{f(t)}{t}\right]^{-1 / \beta}
$$

Model termodifikasi di atas sejauh ini telah berhasil diterapkan pada sampel kristal tunggal yang mengandung kembaran (twinned single crystals) Y-123 dan film tipis $\left.\mathrm{Ti}_{2} \mathrm{Ba}_{2} \mathrm{CaCu}_{2} \mathrm{O}\right) 8+\delta$ (Tl-2212) [3]. Dalam makalah ini, model yang bersangkutan akan diterapkan untuk kristal Bi-2212 yang merupakan bahan SKST yang lebih anisotropis. Hasilnya analisis selanjutnya akan dibandingkan dengan kajian terdahulu yang menggunakan model Fisher, dkk [7, 8].

\section{EKSPERIMEN}

Dua jenis kristal tunggal Bi-2212 yang digunakan dalam kajian ini ditumbuhkan dengan teknik traveling solvent floating zone (TSFZ) menggunakan penumbuh kristal dengan tungku empat cermin buatan Crystal System Inc. Atmosfer penumbuhan dapat diatur, di lingkungan yang mengandung oksigen bertekanan 0,2 dan 2,5 bar untuk masing-masing. Kristal kemudian dianil dengan parameter seperti tercantum dalam oksigen yang bervariasi pada suhu $400^{\circ} \mathrm{C}$ selama 60 jam untuk menghasilkan sampel dengan kandungan oksigen optimal (Bi-OP) dengan nilai $\mathrm{T}_{c, \text { on }}=93 \mathrm{~K}$, serta sampel dengan kandungan oksigen tinggi (Bi-HO) yang memiliki $\mathrm{T}_{c, \text { on }}=70 \mathrm{~K}$. Langkah-langkah dalam eksperimen secara lebih rinci telah diuraikan pada pustaka [7].

Pengukuran resistivitas pada bidang-ab dilakukan dengan metoda 4-probe menggunakan pasta emas sebagai elektroda [7]. Resisitivitas diukur dari suhu ruang dan menurun sampai suhu $10 \mathrm{~K}$ pada medan magnet yang disarahkan sejajar sumbu-c kristal dan bervariasi antara 0 - $40 \mathrm{kOe}$.

\section{ANALISIS DAN PEMBAHASAN}

Ditunjukkan pada Gambar 1 hasil pengukuran resistivitas dua sampel pada bidang-ab sebagai fungsi suhu untuk beberapa nilai medan, $\rho_{a b}(\mathrm{H}, \mathrm{T})$. Resisitivitas dari sampel $\mathrm{Bi}-\mathrm{OP}$ menunjukkan transisi pelehan orde pertama yang dimanifestasian oleh penurunan tajam pada "ekor" kurva resistivitas (tanda panah pada Gambar 1.a), sementara pada sampel Bi-HO hanya terdapat transisi yang landai sehingga dapat ditafsirkan sebagai transisi orde kedua (transisi gelas). Hal ini menunjukkan bahwa doping oksigen menyebabkan terjadinya peningkatan cacat kristal yang bertindak sebagai faktor takteraturan (disorder) dalam kristal, sehinga mengubah corak transisi dari orde satu ke orde kedua.

Selanjutnya dilakukan pencocokan (fitting) garis transisi gelas menurut persamaan : $\mathrm{H}_{g}=\mathrm{H}_{\circ}[\mathrm{f}(\mathrm{t}) / \mathrm{t}]^{1 / \beta}$ dengan $\mathrm{f}(\mathrm{t})=$ $(1-\mathrm{t})$ dan $\mathrm{t}=\mathrm{T} / \mathrm{T}_{c}$. Persamaan diperoleh oleh Rydh, dkk.[3] dengan mangambil nilai $\mathrm{x}=1$, yang sesuai dengan perbandingan energi pining dan energi termal yang keduanya mempunyai nilai sama ketika terjadi transisi gelas. Dari pencocokan kurva diperoleh nilai Ho dan $\beta$ yang meningkat pada kedua sampel seperti tersaji pada Tabel 1 . Khusus tentang nilai $\beta$, diberikan pula pada Tabel 1 data sejenis untuk kristal Y-123 dengan faktor anisotropi $\left(\gamma^{2}\right)$ yang bervariasi dan Tl2212. Tampak dari tabel tersebut bahwa nilai $\beta$ meningkat 

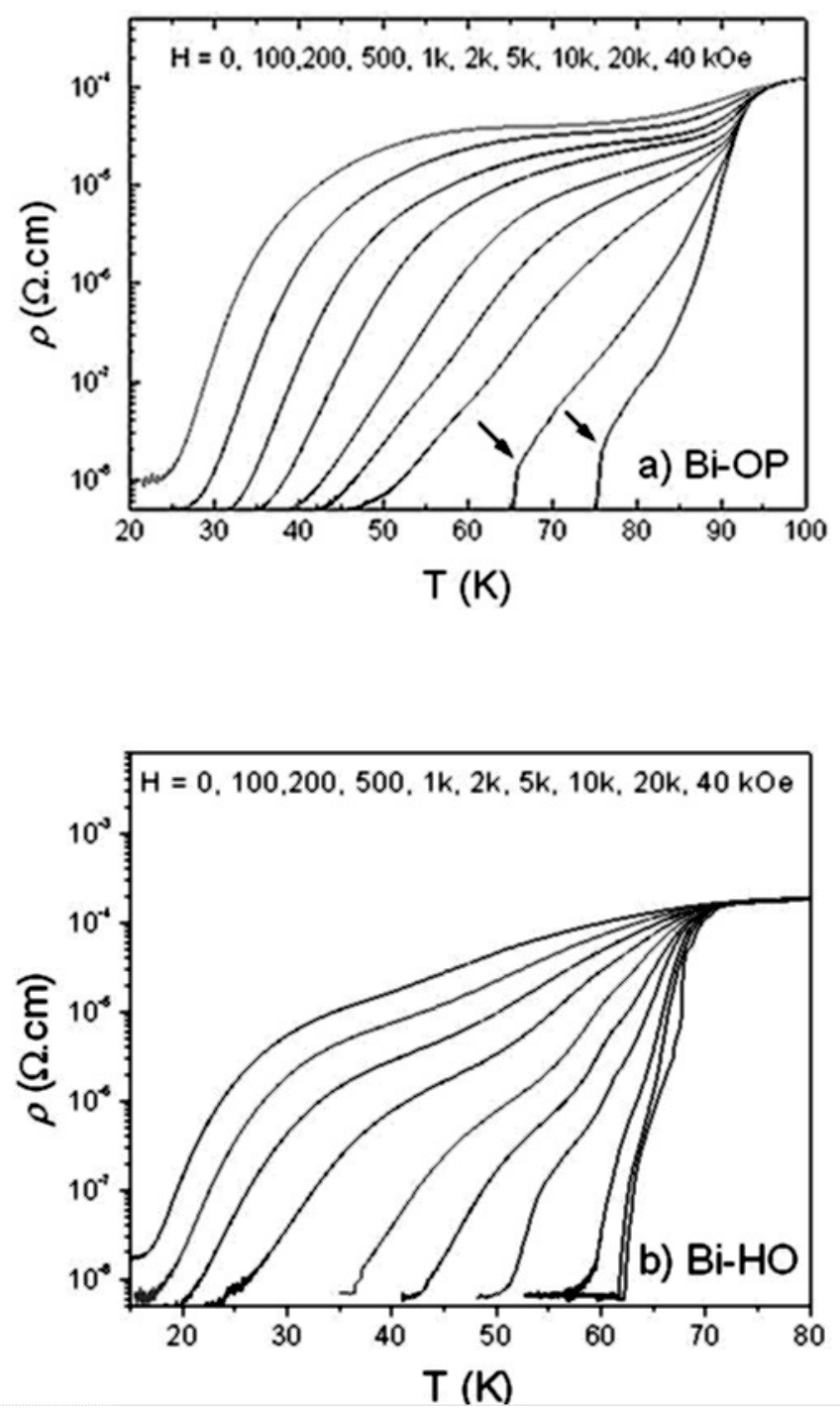

Gambar 1: Kurva resistivitas pada bidang-ab sebagai fungsi dari suhu dan medan magnet yang bervariasi dari 0 sampai dengan 40 kOe, yang diarahkan sejajar sumbu-c: (a). kristal Bi-OP dan b). kristal Bi-HO

dengan berkurangnya nilai faktor anisotropi. Diperoleh kesamaan kecenderungan bahwa nilai $\beta$ berbading terbalik dengan anisotropi untuk kristal yang menjadi kajian dalam penelitian ini maupun kristal lain sebagai pembanding, meskipun nilai suhu kritis $\left(\mathrm{T}_{c}\right)$ berkebalikan.

Selanjutnya dengan persamaan $\mathrm{H}=\mathrm{H}_{o} \mathrm{x}^{-1 / \beta}[\mathrm{f}(\mathrm{t}) / \mathrm{t}]^{1 / \beta}$ dapat dianalisis perilaku vorteks gelasnya. Dalam Gambar 2 medan magnet terskala (scaled) $\mathrm{HHo} / \mathrm{H}_{\rho}(\mathrm{x})$ digambarkan sebagai fungsi dari suhu tereduksi $\mathrm{t}=\mathrm{T} / \mathrm{T}_{c}$ untuk kedua sampel uji yang digunakan. Pada Gambar 2, seluruh data untuk setiap sampel menuju ke dalam satu kurva tunggal. Hal ini mengkonfirmasikan keberadaan $\mathrm{U}_{\circ}$. Penskalaan seperti yang diperlihatkan pada Gambar 2, bersifat tak dapat diduga dan memerlukan asumsi-asumsi empiris dalam teori vorteks gelas. Titik-titik data di dalam Gambar 2 memperlihatkan posisi suhu gelas sebagaimana diperkirakan dengan menerapkan
Tabel I: Parameter-paramater yang diperoleh dari hasil fitting garis gelas kristal Bi-OP dan Bi-HO, sementara nilai $\mathrm{T}_{c}$ dan $\gamma^{2}$ diperoleh dari pustaka [8]. Nilai parameter kristal YBCO-123 dan Tl-2212 diperoleh dari penelitian Rydh, dkk.[3].

\begin{tabular}{ccccc}
\hline \hline Kristal & $\mathrm{T}_{c}(\mathrm{~K})$ & $\gamma^{2}$ & $\mathrm{H}_{o}(\mathrm{Oe})$ & $\beta$ \\
\hline & & & & \\
Bi-OP & 93 & 19.500 & 1.761 & 0,45 \\
$\mathrm{Bi}-\mathrm{HO}$ & 70 & 3.000 & 2.425 & 0,54 \\
Y-123(1) & 52 & 1.225 & - & 0,52 \\
Y-123(2) & 73 & 361 & - & 0,78 \\
Y-123(3) & 86 & 169 & - & 0,80 \\
Y-123(4) & 91 & 76 & - & 0,84 \\
Tl-2212 & 102,5 & - & - & 0,20 \\
& & & & \\
\hline \hline
\end{tabular}

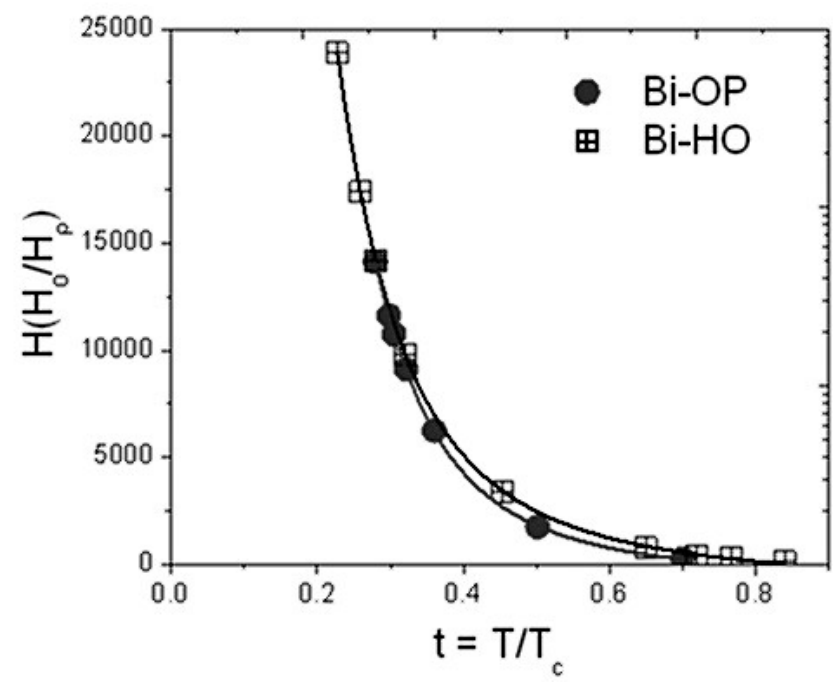

Gambar 2: Medan magnet terskala sebagai fungsi suhu tereduksi untuk sampel yang diteliti. Setiap kurva dibangun dari beberapa tingkat resistivitas yang berbeda dalam daerah gelas terskala

relasi Vogel-Fucher:

$$
\left(\frac{\partial \ln \rho}{\partial T} \propto\left(T-T_{g}\right)\right)
$$

yang menghasilkan eksponen kritis (s) antara 2,9 dan 4,6 ( \pm 0,3) untuk kristal Y-123 dan Tl-2212 [3]. Selanjutnya, dari Gambar 2 menjadi jelas bahwa penskalaan yang dilakukan menghasilkan garis-garis gelas yang akurat untuk sampelsampel yang diamati. Garis-garis transisi gelas akan mengikuti Persamaan (8), seperti hasil penelitian yang dilakukan oleh Rydh, dkk.[3].

Eksponen kritis s dan prefaktor $\rho_{\circ}$ dapat diperoleh secara langsung dengan membuat grafik $\rho$ sebagai fungsi dari $\left|\frac{1}{x}-x\right|$. Untuk mendapatkan nilai $x=\left(\frac{H_{\rho}}{H_{\circ}}\right)$ dari scaling $\frac{H_{\rho}(x)}{H_{\circ}}$, dengan terlebih dahulu mengetahui nilai $\beta$. Penentuan prefaktor $\rho_{\circ}$ diambil nilai ekstrapolasi resistivitas keadaan normal $\rho_{n}$ sehingga $\rho_{\circ}=\rho_{n}$. Gambar 3 memperlihatkan $\frac{\rho_{\circ}}{\rho_{n}}$ sebagai fungsi $\left|\frac{1}{x}-x\right|$ untuk sampel Bi-OP dan Bi- 

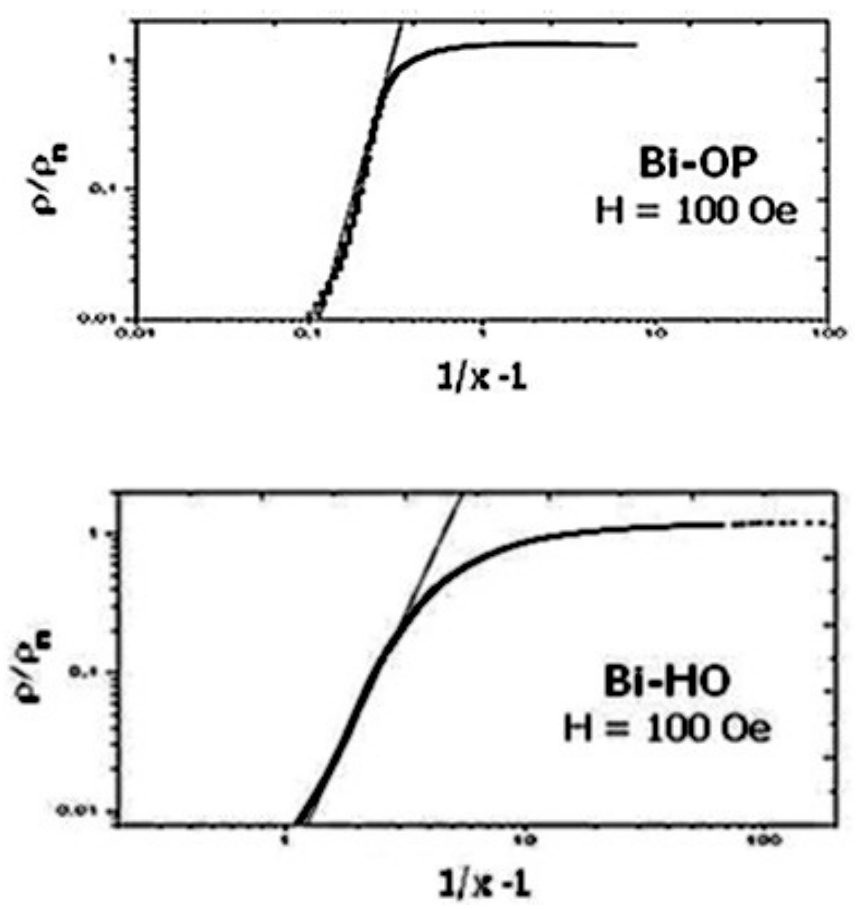

Gambar 3: Resistivitas ternormalisasi $\frac{\rho_{\circ}}{\rho_{n}}$ sebagai fungsi $\left|\frac{1}{x}-x\right|$. Resistivitas normal $\rho_{n}$ diambil dari ektrapolasi dari nilai pada suhusuhu tinggi. Nilai $\beta$ dipilih sedemikian sehingga akan memberikan nilai prefaktor $\rho_{\circ}=\rho_{n}$ untuk resistivitas gelas $\rho_{g}$.

HO. Bagian linier grafik menunjukkan bahwa sampel menunjukkan perilaku vorteks gelas, sedang nilai s diperoleh dari kemiringan kurva linier tersebut.

Gambar 3 adalah salah kurva resistivitas ternormalisasi yang ditujukkan untuk mendapatkan nilai eksponen kritis s pada masing-masing sampel. Untuk lebih jelasnya dapat dilihat pada Tabel 2 yang menunjukkan perbandingan nilai eksponen kritis s yang didapat dengan metode Rydh,dkk. [3]. Nilai tersebut tidak jauh dengan yang didapatkan dalam penelitian oleh Darminto, dkk. [8] yang menggunakan metode Volgel-Fulcher.

Tabel II: Nilai parameter nilai eksponen kritis s untuk sampel Bi-OP dan Bi-HO yang sama dari dua metode yang berbeda. Pada metode Rydh, dkk. merupakan hasil dari penelitian ini sedangkan metode Vogel-Fulcher diperoleh dari penelitian sebelumnya yang dilakukan oleh Darminto, dkk.[8]

\begin{tabular}{lcc}
\hline \hline Sampel & s (metode Rydh, dkk) & s (metode Vogel-Fulcher) \\
\hline \multirow{2}{*}{ Bi-OP } & $4,7 \pm 1,7$ & $5,3 \pm 1,3$ \\
Bi-HO & $2 \pm 0.4$ & $2,8 \pm 0,6$ \\
\hline \hline
\end{tabular}

Selain itu, sampel Bi-OP dan Bi-HO mempunyai nilai s yang sesuai dan konsisten dengan hasil penelitian sebelumnya untuk kristal tunggal Bi-2212 murni sebesar $7 \pm 1$ [9] dan sampel kristal tunggal Y-123 seperti telah diberikan pada bagian sebelumnya. Dalam Tabel 2 tampak nilai s dari Y-123 dan Tl-2212 tidak jauh berbeda dengan nilai s sampel Bi-OP dan Bi-HO.

Selain itu nilai s yang menurun untuk kedua sampel sesuai dengan yang diharapkan di mana nilai s mencerminkan tingkat takteraturan sampel, sesuai dengan penelitian sebelumnya pada 3 jenis sampel Bi-2212 berbeda yang dilakukan oleh Mustari [10] deangan metode Vogel-Fulcher, s semakin turun dengan kandungan doping oksigen yang semakin besar.

\section{SIMPULAN}

Berdasarkan analisis yang telah dilakukan terhadap kristal tunggal Bi-2212 dengan doping optimal (Bi-OP) dan doping sangat berlebih (Bi-HO) diperoleh kesimpulan bahwa penggambaran transisi gelas dengan model transisi gelas Fisher termodifikasi (Rydh, dkk. [3]) dapat diterapkan pada material yang lebih anisotropi dan didapatkan penjelasan yang konsisten. Kajian seperti ini belum didapatkan sebelumnya pada sampel Bi-2212. Karakterisasi vorteks berdasarkan parameter $\beta$ dari 4,5 menjadi 5,4 (naik) seiring dengan penurunan anisotropi berkaitan dengan semakin naiknya kandungan oksigen dan mencerminkan penguatan vorteks. Selain itu, model ini menghasilkan eksponen kritis (s) dari 4,7 menjadi 2 (turun) pada kedua sampel yang mencerminkan peningkatan tingkat takteraturan pada kristal Bi-2212.

\section{Ucapan Terima Kasih}

Sebagian penelitian ini dibiayai oleh The Third World Academy of Sciences (TWAS), Trieste, Italy, melalui Research Grant Programme No. : 04-236 RG/PHYSICS/AS.
[1] M. Cyrot \& D. Pavuna, Introduction to Superconductivity and High Tc Materials, Singapore. World Scientific (1992).

[2] L.F. Cohen \& H.J. Jansen, Rep.Prog. Phys. 60, 1581 (1997).

[3] A. Rydh, . Rapp and M. Andersson, Phys. Rev. Lett. 83, 1850 (1999).
[4] M. P. A. Fisher, Phys. Rev. Lett. 62, 1415 (1989).

[5] R. H. Koch, V. Foglietti, W. J. Gallagher, G. Koren, A. Gupta, and M. P. A. Fisher, Phys. Rev. Lett. 63, 1511 (1989).

[6] D. S. Fisher, M. P.A Fisher, and D. A. Huse, Phys. Rev. B 43, 130 (1991). 
[7] Darminto, M.O. Tjia, A.A. Nugroho, A.A. Menovsky, J. Shimoyama, K. Kishio, Physica C 357-360, 617 (2001).

[8] Darminto, M. Diantoro, I.M. Sutjahja, A.A. Nugoho, W. Loeksmanto, M.O. Tjia, Physica C 378-381, 479 (2002).

[9] H. Safar, P.L. Gammel, D.J. Bishop, D.B. Mitzi and A. Kapitul- nik, Phys. Rev. Lett., 68, 2672 (1992)

[10] Mustari, Analisa Magneto-resistivitas pada Fase Gelas Vorteks dari Superkonduktor Kristal Tunggal $\mathrm{Bi}_{2} \mathrm{Sr}_{2} \mathrm{CaCu}_{2} \mathrm{O}_{8+\delta}$, Tesis S2, Fisika FMIPA ITS, Surabaya (2006). 